\title{
Are Teachers Standing Too Much at Work?
}

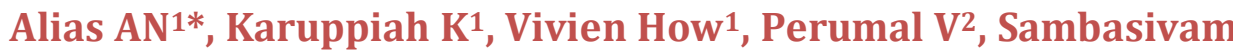 \\ $\mathrm{S}^{1}$, Tamrin SBM${ }^{1}$ \\ ${ }^{1}$ Department of Environmental \& Occupational Health, Faculty of Medicine and \\ Health Sciences, Universiti Putra Malaysia, Malaysia \\ 2Industrial Design Department, Faculty of Design \& Architecture, Universiti Putra \\ Malaysia, Malaysia
}

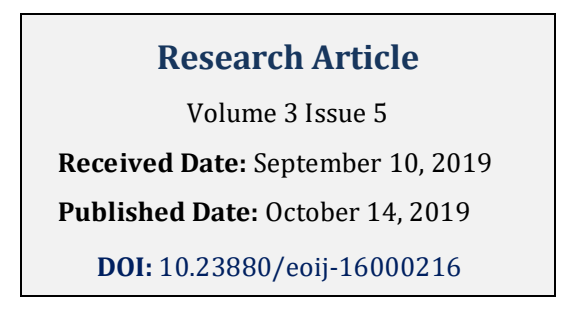

*Corresponding author: Karmegam Karuppiah PhD, Department of Environmental \& Occupational Health, Faculty of Medicine and Health Sciences, Universiti Putra Malaysia, 43400 Serdang, Selangor, Malaysia, Tel: +603-8947 2513; Email: megam@upm.edu.my

\section{Abstract}

Limited standing working conditions such as prolonged standing work or static working posture among teachers is a common sight in the classroom, especially during school hours. From the perspective of this article working in a prolonged static standing working posture is very disadvantageous since the lower extremities would fully support the total body weight of a teacher. This will result in continuous loading on the lower extremities such as the knee joints and particularly the feet, leading to the incidence of discomfort and pain. In appreciation of the significance of managing standing jobs among teachers, this article was ready to disseminate data on prolong-standing health effects and intervention methods associated with teaching practices. This information may be helpful as a guideline for improving their school management to improve occupational health among teachers.

Keywords: School Teacher; Musculoskeletal Disorders; Prolong Standing

\section{Background}

In essence, a teacher is expected to keep a right standing posture when giving classes in a lesson by putting one foot up, frequent adjusting position and maintaining the job at a pleasant height from wearing shoes with heal for long periods [1]. Standing is one of the most favoured working positions in many sectors as it offers a significant degree of physical freedom and mobility to humans. Furthermore, the cognitive views of increasing work efficiency and productivity level among human are the factors this working position is practiced. However, standing upright for a long time or otherwise known as prolonged standing often contributes to physiological pain, fatigue, and even health problems such as musculoskeletal disorders (MSDs) [2]. The Oxford Dictionary described 'stand' or 'standing' as keeping upright, backed by one's feet, while 'prolonged' is continuing for a long time or longer than usual. A teacher is regarded to be subjected to prolonged standing if he or she spent over half of the school hours every day in standing posture [3]. Subsequently, when teachers have invested a lengthy time of energy in a standing posture all through their working hour, they may experience pain and muscle exhaustion at the end of the working day. They will have possibly suffered musculoskeletal injuries in the lengthy run [4]. 


\section{Ergonomics International Journal}

\section{Discussion}

\section{Work-Related (WMSD) \\ Musculoskeletal Disorders}

Work-related musculoskeletal disorders (WMSD) refer to circumstances where the person has encountered discomfort in one or more areas of the body (neck, shoulder, back, elbow, hand, hip and feet), joint torment, tingling and inflammation [5]. As a prevalent symptom, a prolong-standing worker may encounter pain in the legs, neck, and shoulder. On the off chance that standing position is consistently rehearsed and cure activities are taken inactively, they may experience distress and exhaustion particularly in the lower appendage muscles (legs and thighs), lower back, and feet. As long-haul impacts extended-standing prompts genuine medical problems, for example perpetual venous ailment, circulatory issues, the chance of increased danger of stroke, difficulty in pregnancy and degenerative harm to the joints of the spine, lower legs and legs [4]. Standing duration also recognized as an important contributor to WMSD. When person conduct work tasks in a standing place for over 4 hours every day, they are potentially exposed to WMSD associated with lower back pain [6]. Late research uncovered that about half of healthy participants reported pain in the lower back, despite the fact they were oppressed following 2 hours of prolonged standing [7]. Despite discomfort and pain in the lower back, prolong standing likewise triggered pain in the feet. Research revealed that pain in the feet is frequently recorded in standing posture relative to sedentary or walking tasks [8].

Worries about the danger of WMSD have expended in the globe of education, teachers specifically have a raised rate of WMSD contrast with other occupational groups, with an incidence in the range of $45 \%$ and 95\% [9]. Repetitive strains injuries, which often cause problems in teachers' upper muscles have resulted of prolonged standing posture [10]. Prolonged standing is engaged in writing on white and blackboards, monitoring students' work and performance at their desks and learning tasks [11]. According to the study was done in Pahang, Malaysia, prolonged standing is the most significant risk factors (23.4\%) among teachers [12]. Physical efforts during educating, prolonged standing inside the classroom inappropriately for several hours resulted in musculoskeletal pain (MSP) among teachers. All teachers shared the same standing position in favour of developing lower back pain. Standing up is not just factor contributing MSP, however different conditions, for example, carrying material to class or study hall, introducing equipment/teaching tools, strolling inside and outside school can further aggravate pain [12].

\section{Applications and Intervention for MSDs}

Despite this, there are prospective applications and interventions that can be changed to be executed among school teachers for counteractive action and control of WMSD. New techniques for evaluating WMSD are required with the improvement of WMSD-related studies. Interventions relying on occupational health education lectures, on-site ergonomics guidance, promoting pamphlets and handouts demonstrated a beneficial impact on the counteractive action and control of WMSD among school teachers. Improvement in awareness, behaviour and attitude changes were discovered in 6- and 12-months post-interventions, affirming that the program's viability can be kept up. In order to help proofbased ergonomic interventions in practice, further excellent studies, expanding the number of observations over time or broadening the length of the study are required. According to a study was done in Egypt, prolonged standing, awkward postures and inappropriate furniture are critical threat variables for MSP among physical factors and a health promotion intervention has been recommended to limit MSP from developing among teachers [13].

The complicated nature of MSD threats variables in advanced and developing nations indicates that any single intervention approach would likely be suboptimal in decreasing MSD among school teachers. Indeed, if little or no effort is made to decrease the incidence level of this important workplace issue, MSD may lead to decreased efficiency of teachers that may contribute to harmful results of students, enhanced sick leave, ill-health, premature pension or enhanced health care expenses. Cost-effective intervention policies are especially crucial for emerging nations. Therefore, to help relieve the strain among teachers in these regions, as elsewhere higher emphasis must be put on increasing consciousness of MSD. Awareness and understanding of the relationship between school teaching and MSD are essential in order to prevent MSD and minimize its progress [14].

In discussing the severe issues of MSD in the learning industry, ergonomics training particular to MSD risk factors and prevention should now be implemented into teachers' training facilities, while refresher classes related to teachers' work task and workstation should also be implemented for in-service teachers. Since most MSD surveys conducted among teachers have concentrated on recall data and self-reported MSD, a potential study may 


\section{Ergonomics International Journal}

require clinical diagnosis of MSD and its seriousness, an ideal partner undertaken with longitudinal studies [14]. For great benefit, teachers should be provided with free health screening every year. Health screening for musculoskeletal problems can identify issues and inform teachers how to decrease the effect. MSDs health screening is intended to monitor teachers proactively and recognize significant factors that may lead to MSDs and overall health circumstances. This approach seeks to participate teachers in taking accountability for their health and helps to decrease the future effect on their well-being and workability. The main objective for this health screening will help to reduce MSDs, recognize any existing MSDs or potential areas of concern, educate teachers regarding good relation working practices and postures, provide particular work-related functional activities and lastly encourage teachers to obtain and retain their overall fitness rates. Recommended rehabilitation program from the results of health screening should be enhanced both musculoskeletal pain and dysfunction, while teachers enhanced overall health and fitness should improve their long-term capacity to work and productivity during school hours.

\section{Conclusion}

Concerning adverse effects of prolonged standing among teachers, studies and intervention should be regarded as a priority so that associated health effects can be eliminated or minimized. In the fields of ergonomics, engineering controls have been discovered to be efficient ways of reducing the risk of WMSD and due to prolonged standing exposures; numerous interventions have been recorded in engineering controls to improve occupational health among workers in industrial fields. Engineering control can be applied to school teachers such as application of ergonomic footwear design that can release muscle fatigue and discomfort in the lower body due to prolonged standing. User preferences for work footwear and work-related MSD issues have been mainly ignored among workers especially school teachers that are in a prolonged standing job setting most of the school hours. Comfort footwear intervention is therefore novel and offers a starting point from which the broader problems can be explored.

\section{References}

1. Darwish MA, Al-Zuhair SZ (2013) Musculoskeletal pain disorders among secondary school saudi female teachers. Pain Research and Treatment 2013: 1-7.
2. Mohd Noor SNA, Ahmad IN, Wahab NA, Nor Ma'arof MI (2013) A review of studies concerning prolonged standing working posture. Advanced Engineering Forum, Trans Tech Publications, Switzerland 10: 131136.

3. (2019) Oxford Dictionaries: The World's most trusted dictionaries.

4. Halim I, Omar AR (2011) A review on health effects association with prolonged standing in the industrial workplaces. IJRRAS 8(1): 14-21.

5. Lafond D, Champagne A, Descarreaux M, Dubois JD, Prado JM, et al. (2009) Postural control during prolonged standing in persons with chronic low back pain. Gait \& Posture 29(3): 421-427.

6. Magora A (1972) Investigation of the relation between low back pain and occupation. three physical requirements-sitting, standing, and weight lifting. IMS Ind Med Surg 41(12): 5-9.

7. Gregory DE, Callaghan JP (2008) Prolonged standing as a precursor for the development of low back discomfort: an investigation of possible mechanisms. Gait \& Posture 28(1): 86-92.

8. Hansen L, Winkel J, Jorgensen K (1997) Significance of mat and shoe softness during prolonged work in upright position: based on measurements of low back muscle EMG, foot volume changes, discomfort and ground force reactions. Applied Ergonomics 29(3): 217-224.

9. Shuai J, Yue P, Li L, Wang S (2014) Assessing the effects of an educational program for the prevention of work-related musculoskeletal disorders among school teachers. BMC Public Health 14: 1211.

10. Chaiklieng S, Suggaravetsiri P (2012) Risk factors for repetitive strain injuries among school teachers in Thailand. Work: A Journal of Prevention Assessment and Rehabilitation 41(S1): 2510-2515.

11. Nur Farahwahida MA, Irniza R, Suhainizam MS, Emilia ZA (2016) Work task and job satisfaction predicting low back pain among secondary school teachers in Putrajaya. Iranian Journal of Public Health 45(S1): 8592.

12. Balakrishnan R, Chellapan ME, Thenmozhi (2016) Prevalence of low back pain and its risk factors among secondary school teachers at Bentong, Pahang. 


\section{Ergonomics International Journal}

International Journal of Physical Education, Sports and Health 3(2): 35-40.

13. Ebied EMES (2015) Work-related musculoskeletal pain among primary school Teachers: A recommended health promotion intervention for prevention and management. World Journal of Nursing Sciences 1(3): 54-61.
14. Erick PN, Smith DR (2015) Musculoskeletal disorders in the teaching profession: An emerging workplace hazard with significant repercussions for developing countries. Ind Health 53(4): 385-386. 